\title{
CLINICAL PROFILE OF ENDOMETRIAL CARCINOMA
}

\author{
Subhalakshmi Manappat Subrahmanian'1, Priya V2
}

${ }^{1}$ Senior Resident, Department of Obstetrics and Gynaecology, Government Medical College, Kottayam.

${ }^{2}$ Assistant Professor, Department of Obstetrics and Gynaecology, Government Medical College, Kottayam.

\section{ABSTRACT}

\section{BACKGROUND}

Endometrial carcinoma is a disease of old women, typically arising in the sixth and seventh decades of life. In women of younger age groups, endometrial carcinoma is uncommon. These women have traditionally been thought to present with favourable pathological form.

\section{MATERIALS AND METHODS}

Study was conducted in the Department of Gynaecology in Medical College Hospital, Kottayam. Ethical Committee approval was taken. Data of women who were treated surgically for histologically proven carcinoma of endometrium were taken. A five-year retrospective data was analysed. Based on age, they were divided into two age groups.

Group A: Women aged less than 40 years.

Group B: Women aged 40 years or more.

Exclusion Criteria- Women who were treated initially by chemotherapy, radiotherapy or its combination.

Statistical analysis was performed using SPSS software (version 16).

\section{RESULTS}

In younger patients (Group A), most common presenting symptom was menorrhagia and they presented with higher grades of histology (papillary carcinoma endometrium 78.9\%) and with advanced stage of disease. Most common presenting symptom in Group B was post-menopausal bleeding with a history of discharge per vaginum (10.7\%) than Group A (5.3\%). In Group B, majority of patients presented with endometrioid histology (87.1\%) and most of them (47.9\%) had early stage of disease. Clear cell histology was observed only in Group B (2.9\%). Group A patients had their treatment delayed, as diagnosis was made later.

\section{CONCLUSION}

In patients less than 40 years, early intervention in the form of early decision for pathological sample taken via fractional curettage and its reporting may result in early detection of carcinoma at an earlier stage and with a good histological grading. Since some of fractional curettage reports of endometrial hyperplasia with atypia turned out to be carcinoma endometrium, these atypical hyperplasia changes must be evaluated properly. This can further be helped by ultrasonography or magnetic resonance imaging.

\section{KEYWORDS}

Clinical Profile, Carcinoma, Endometrium, Histopathology.

HOW TO CITE THIS ARTICLE: Subrahmanian SM, Priya V. Clinical profile of endometrial carcinoma. J. Evolution Med. Dent. Sci. 2017;6(22):1804-1807, DOI: 10.14260/Jemds/2017/396
BACKGROUND
Endometrial carcinoma is a disease of old women, typically arising in the sixth and seventh decades of life. In women of younger age groups, endometrial carcinoma is uncommon. These women have traditionally been thought to present with favourable pathological form. Endometrial carcinoma is the fourth most common cancer in women worldwide and is the eighth most common cause of death from malignancy. ${ }^{1}$ Each woman is at $2.8 \%$ lifetime risk of developing endometrial carcinoma. $^{2}$ Worldwide each year 2,87,100 women are diagnosed with this cancer. ${ }^{3}$ The peak incidence occurs in age group 55 - 65 years. Previously, the disease was uncommon in younger women.
However, recently there have been an increased risk of carcinoma endometrium in younger age groups, and most of them will have higher grade pathology. The morbidity created by this disease is higher in younger women. Here this study gains importance, which is to know the clinical profile of carcinoma endometrium in women of two age groups.
Often carcinoma endometrium present as an early stage disease and often managed without radiotherapy or radical surgery, but the death from carcinoma endometrium exceeds that from carcinoma cervix. This is because of early detection of carcinoma cervix by various screening methods. Here, discussing various clinical presentation and types of endometrial carcinoma encountered in our department.

Financial or Other, Competing Interest: None.

Submission 07-02-2017, Peer Review 28-02-2017,

Acceptance 09-03-2017, Published 16-03-2017.

Corresponding Author:

Subhalakshmi Manappat Subrahmanian,

Jyothis, Manganam,

P. O, Kottayam-686018,

Kerala.

E-mail:drsubhalakshmims@gmail.com

DOI: $10.14260 /$ jemds $/ 2017 / 396$

\section{MATERIALS AND METHODS}

Study was conducted in the Department of Gynaecology in Medical College Hospital, Kottayam. Ethical Committee approval was taken. Data of women who were treated surgically for histologically proven carcinoma endometrium were taken. A five-year retrospective data was analysed. Based on age, they were divided into two age groups.

- Group A: women aged less than 40 years.

- Group B: women aged 40 years or more. 
Patients were identified and their medical register were taken from tumour registry data in Department of Obstetrics and Gynaecology and from Department of Pathology in Government Medical College, Kottayam.

\section{Inclusion Criteria}

Women diagnosed histologically as carcinoma endometrium and who were treated by primary surgical management.

\section{Exclusion Criteria}

Women who were treated initially by chemotherapy, radiotherapy or its combination.

Clinical profile of patients regarding age, parity, clinical presentation (symptoms), menopausal status, family history of malignancy were initially taken. Later their intraoperative findings were analysed regarding staging of disease. Also, analysis regarding preoperative histopathology report of endometrial curettings that lead to the diagnosis of endometrial malignancy were studied. These patients' postoperative histopathology reports of the specimen were collected from register. This was also assisted by taking data from register in Pathology Department.

\section{Statistical Method}

Statistical analysis was performed using SPSS software (version 16). Descriptive statistics and inferential statistics with 95\% confidence limits were calculated. Difference between groups were evaluated using chi square test.

\section{RESULTS}

In younger patients (Group A), most common presenting symptom was menorrhagia and they presented with higher grades of histology (papillary carcinoma endometrium $78.9 \%$ ) and with advanced stage of disease. Most common presenting symptom in Group B was post-menopausal bleeding with a history of discharge per vaginum (10.7\%) than Group A (5.3\%). In Group B, majority of patients presented with endometrioid histology (87.1\%) and most of them (47.9\%) had early stage of disease. Clear cell histology was observed only in Group B (2.9\%). Group A patients had their treatment delayed as diagnosis was made later.

\begin{tabular}{|c|c|c|c|c|c|c|}
\hline \multirow{2}{*}{$\begin{array}{c}\text { History of } \\
\text { Menorrhagia }\end{array}$} & \multicolumn{4}{|c|}{ Age } & \multicolumn{2}{|}{ Total } \\
\cline { 2 - 7 } & $\mathbf{4 0}$ & \multicolumn{2}{|c|}{$\geq \mathbf{4 0}$} & \multicolumn{2}{|c|}{ No. } & $\%$ \\
\hline Nos & 19 & 100.0 & 7 & 5.0 & 26 & 16.4 \\
\hline No & 0 & .0 & 133 & 95.0 & 133 & 83.6 \\
\hline Total & $\mathbf{1 9}$ & $\mathbf{1 0 0 . 0}$ & $\mathbf{1 4 0}$ & $\mathbf{1 0 0 . 0}$ & $\mathbf{1 5 9}$ & $\mathbf{1 0 0 . 0}$ \\
\hline Table 1. Table showing Menorrhagia History in Patients \\
\hline
\end{tabular}

Chi square $=110.4, p=.000$

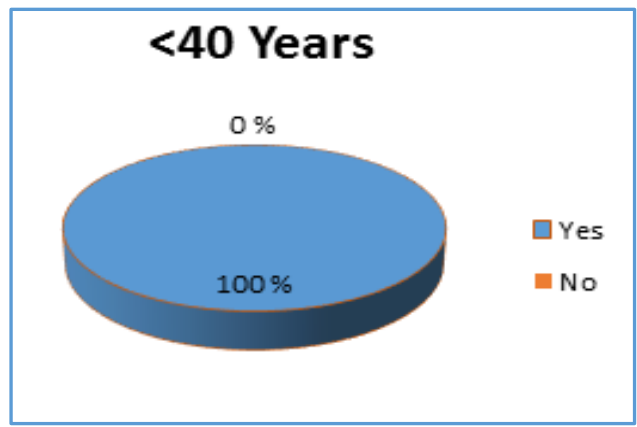

Figure 1. History of Menorrhagia in Group A

\section{$\geq 40$ Years}

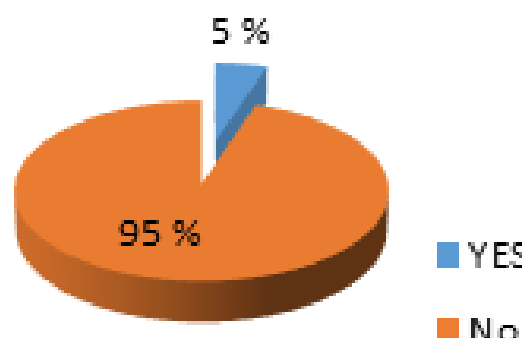

No

Figure 2. History of Menorrhagia in Group B

In Group B, 10.7\% presented with discharge per vaginum while in Group A 5.3\% had discharge per vaginum along with menorrhagia. But women in Group B had more tendency to present with discharge per vaginum.

\begin{tabular}{|c|c|c|c|c|c|c|}
\hline \multirow{2}{*}{$\begin{array}{c}\text { History of } \\
\text { Discharge PV }\end{array}$} & \multicolumn{4}{|c|}{ Age } & \multirow{2}{*}{ Total } \\
\cline { 2 - 7 } & $\mathbf{4 0}$ & $\mathbf{4}$ & No. & $\mathbf{\%}$ & No. & $\%$ \\
\hline Yes & 1 & 5.3 & 15 & 10.7 & 16 & 10.1 \\
\hline No & 18 & 94.7 & 125 & 89.3 & 143 & 89.9 \\
\hline Total & 19 & 100.0 & $\mathbf{1 4 0}$ & $\mathbf{1 0 0 . 0}$ & 159 & $\mathbf{1 0 0 . 0}$ \\
\hline Table 2. Table showing Discharge per Vaginum in Patients \\
Studied \\
\hline
\end{tabular}

Chi square $=.549, \mathrm{p}=.738$

\section{$<40$ Years}

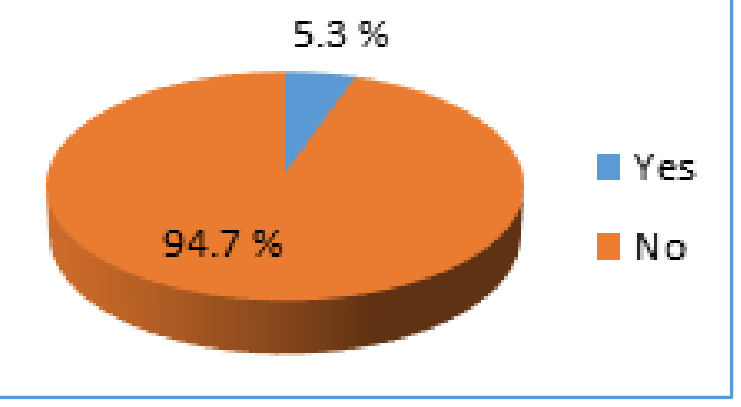

Figure 3. History of Discharge per Vaginum in Group A

\section{$\geq 40$ Years}

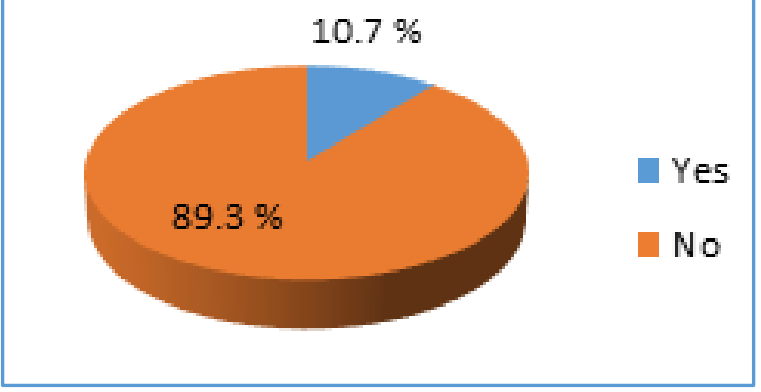

Figure 4. History of Discharge per Vaginum in Group B 
Most of the patients in Group B who presented with carcinoma endometrium were postmenopausal (95\%). Regarding the family history in Group A 5.3\% presented with family history of Carcinoma endometrium, while in Group B it was 3.6\%. In Group B 2.9\% women, each had family history of Carcinoma colon and Carcinoma breast respectively. Also $1.4 \%$ women in Group B had history of carcinoma ovary in their family.

On analysing adnexal involvement, 7.9\% presented with an ovarian mass. In Group B, $1.4 \%$ had parametrial involvement, while none of the patients in Group A had parametrial involvement. Hence, it was concluded that patients in Group B have more tendency to present with an adnexal mass or parametrial involvement. In Group A, 73.7\% presented with histopathology report of carcinoma endometrium, $15.8 \%$ had complex hyperplasia with atypia, $5.3 \%$ each with simple hyperplasia and simple hyperplasia with atypia. In Group B 75.7\% had fractional curettage showed histopathology of Carcinoma endometrium, 10.7\% had complex hyperplasia with atypia, $8.6 \%$ had simple hyperplasia with atypia. Madhuri N Bhagde also has the same study result that the histopathology of endometrial curettings may not always help in diagnosing endometrial Carcinoma. ${ }^{4} \mathrm{~A}$ strong suspicion is needed to diagnose this in patients, especially in premenopausal or perimenopausal age groups. In Group A, 26.3\% presented with Stage 1B followed by $21.1 \%$ each by Stage IIIA and Stage IA. None of them presented with Stage IIIC2 and above. In Group B, 42.1\% presented with Stage 1A followed by $37.1 \%$ with Stage IB, $7.9 \%$ presented with Stage IIIA. None of them presented with Stage IIIC2 and above. In study by Uharcek Petal, they found that the deeper myometrial invasion was significantly associated with age. ${ }^{5}$ Endometrial adenocarcinoma was the most common histological form of endometrial carcinoma in Group B (87.9\%), while in Group A 78.9\% presented with papillary serous histology. Only $21.1 \%$ patients had endometrial adenocarcinoma histology in Group A, moreover none of the patients had clear cell or other rare varieties of histology. On the other hand, in Group A, 10.1\% patients presented with adenocarcinoma histology and $2.9 \%$ patients with clear cell histology. So in Group A, patients were presenting with more aggressive form of histology compared to Group B. Among total, commonest histological type after surgery was adenocarcinoma (79.2\%). In Group A, papillary carcinoma $78.9 \%$ were common than adenocarcinoma.

\begin{tabular}{|c|c|c|c|c|c|c|}
\hline \multirow{2}{*}{$\begin{array}{c}\text { Tissue } \\
\text { Biopsy HPR }\end{array}$} & \multicolumn{4}{|c|}{ Age } & \multicolumn{2}{|}{ Total } \\
\cline { 2 - 7 } & $\mathbf{4 0}$ & \multicolumn{2}{|c|}{$\geq \mathbf{4 0}$} & \multicolumn{2}{|c|}{} \\
\cline { 2 - 7 } & No. & $\mathbf{\%}$ & No. & $\mathbf{\%}$ & No. & $\%$ \\
\hline Adeno Ca & 4 & 21.1 & 122 & 87.1 & 126 & 79.2 \\
\hline $\begin{array}{c}\text { Papillary } \\
\text { Serous }\end{array}$ & 15 & 78.9 & 14 & 10.0 & 29 & 18.2 \\
\hline Clear Cell & 0 & .0 & 4 & 2.9 & 4 & 2.5 \\
\hline Total & $\mathbf{1 9}$ & $\mathbf{1 0 0 . 0}$ & $\mathbf{1 4 0}$ & $\mathbf{1 0 0 . 0}$ & $\mathbf{1 5 9}$ & $\mathbf{1 0 0 . 0}$ \\
\hline Table 3. Tabble showing Tissue Biopsy Histopathology \\
Report in Two Age Groups \\
\hline
\end{tabular}

Chi square $=53.3, \mathrm{p}=.000$

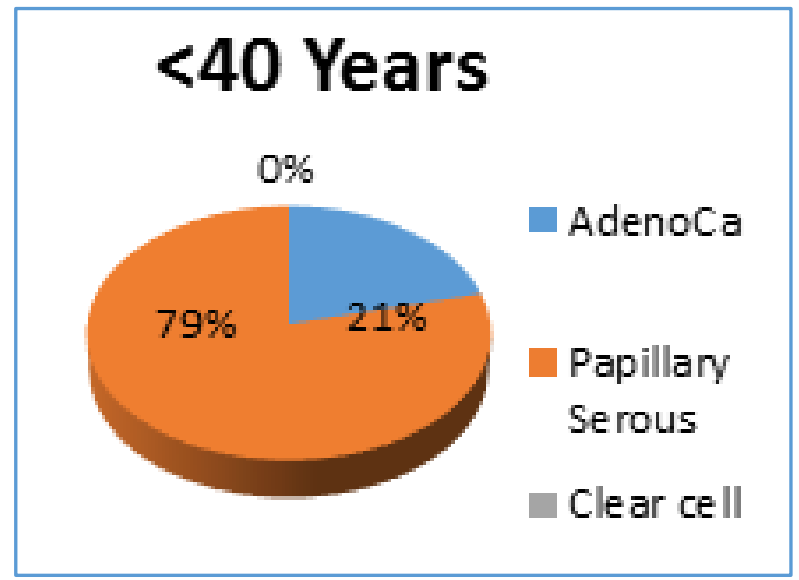

Figure 5. Histopathology Report in Group A

\section{$\geq 40$ Years}

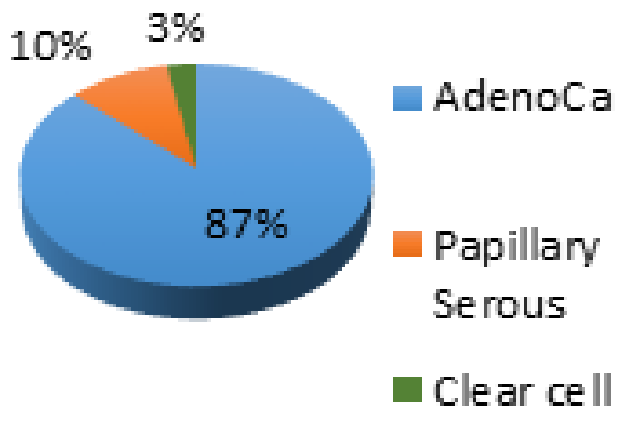

Figure 6. Histopathology Report in Group B

In study by Madhuri $\mathrm{N}$ Bhagde, $71.43 \%$ were adenocarcinoma. ${ }^{4}$ Conversely, in Japan Kaku et al said that patients younger than 40 years had endometrioid histology and well-differentiated histology. ${ }^{6}$ In Group A 47.4\% presented with moderately differentiated histological grading, 26.3\% each presented with Grade 1 and Grade 3. In Group B 76.4\% presented with well-differentiated grading of histology $11.4 \%$ with Grade 2, $12.1 \%$ with Grade 3. So Group A presented with higher degree of histology, while in Group B $76.4 \%$ presented with lower degree of differentiation. Pellerin et al found that $52.6 \%$ had Grade 1 histology, $26.3 \%$ had Grade 2 and 21.1\% had Grade 3 histology.7 Their study concluded that younger age group had lower incidence of advanced stage of disease, higher degree of tumour differentiation.

\section{DISCUSSION}

Endometrial carcinoma is one of the leading site of carcinoma in Indian females with an age adjusted incidence rate vary from 4.8 to 2.7 per 100,000 across different carcinoma regions. ${ }^{8}$

In the retrospective study of 159 patients diagnosed with Carcinoma endometrium admitted in the Department of Obstetrics and Gynaecology in Government Medical College, Kottayam, 19 were younger than 40 years at the time of diagnosis (11.9\%) and $150(88.1 \%)$ were 40 years and older. Among all patients, $89.3 \%$ were multiparous and $10.7 \%$ were nulliparous). Study by Manchana et al in Thailand found out 
that up to $10 \%(42 / 423)$ of endometrial adenocarcinoma, patients were younger than age of 40 years. ${ }^{9}$ The higher incidence of nulliparity was significantly demonstrated in Group A (less than 40 years) 80 .

In patients aged more than 40 years, majority of patients were multiparous, similar was the percentage of multiparas in age less than 40 years (63.2\%). Among nulliparous, Group A had a higher chance of developing Carcinoma endometrium. In a study conducted by Gallup et al, nulliparity among Group A were 44\% and in Group B 10.5\%.10 Our study found that nulliparous among Group A were 36.8\% and Group B were 7.1\%. In Group A nulliparous had a more chance of Carcinoma endometrium (chi square being 15.5 and $p$ value .000). Nulliparous had more chance of developing Carcinoma endometrium early, especially in Group A. In Group A all of them presented with menorrhagia, while in Group B 5\% only presented with menorrhagia.

\section{CONCLUSION}

In this study, the overall distribution of tumour stage and grade were not of the same for younger women and the older women. Younger women with endometrial carcinoma are found to be at higher risk. Patients less than 40 years had higher incidence of advanced stage disease and higher degree of tumour differentiation. Reason for advanced stage of the diagnosis in younger group in our study may be due to delay in seeking health access.

\section{REFERENCES}

[1] Siegel R, Ward E, Brawley 0, et al. Cancer statistics, 2011: the impact of eliminating socioeconomic and racial disparities on premature cancer deaths. CA Cancer J Clin 2011;61(4):212-36.
[2] Cancer of the Endometrium-SEER Stat Fact Sheets. [Cited May 29, 2016]. Available from: http://seer.cancer.gov/statfacts/html/corp.html

[3] Cancer of the Endometrium-SEER Stat Fact Sheets. [Cited Feb 3, 2017] http://seer.cancer.gov/stat facts/html/corp.html

[4] Bagde MN. Unique clinicopathologic features of endometrial malignancy in a tertiary care institute-a five year Indian rural experience. The Experiment 2015;32(3):2057-65.

[5] Uharček P, Mlynček M, Ravinger J, et al. Prognostic factors in women 45 years of age or younger with endometrial cancer. Int J Gynecol Cancer 2008;18(2):324-8.

[6] Kaku T, Matsuo K, Tsukamoto N, et al. Endometrial carcinoma in women aged 40 years or younger: a Japanese experience. Int J Gynecol Cancer 1993;3(3):147-53.

[7] Pellerin GP, Finan MA. Endometrial cancer in women 45 years of age or younger: a clinicopathological analysis. Am J Obstet Gynecol 2005;193(5):1640-4.

[8] National Cancer Registry Programme [Cited Feb 3, 2017] http://www.ncrpindia.org/

[9] Manchana T, Khempech N. Endometrial adenocarcinoma in young Thai women. Asian Pac J Cancer Prev 2008;9(2):283-6.

[10] Gallup DG, Stock RJ. Adenocarcinoma of the endometrium in women 40 years of age or younger. Obstet Gynecol 1984;64(3):417-20. 